\title{
Can dietary flavonoids influence the development of coronary heart disease?
}

\author{
By Helle Margrete Meltzer and Karl Egil Malterud
}

\begin{abstract}
The flavonoids constitute a large group of secondary plant metabolites being ubiquitous among higher plants. The biological activity of flavonoids was discovered during the $1930 \mathrm{~s}$, when it was found that several vegetables and fruits contained substances different from vitamin $\mathrm{C}$ and yet able to counteract the capillary fragility characteristic of scurvy. The "P vitamins" (as they were once called) were, however, not accepted as vitamins, and they are now regarded as members of the large and diffuse class of "non-nutrients". Today, extensive research is directed towards the elucidation of the importance and the potential therapeutic value of flavonoids in the treatment of, e.g., cancer and cardiovascular diseases. In this paper, recent research on flavonoids is reviewed with emphasis on the possible correlation between dietary flavonoid content and reduced risk for cardiovascular disease.
\end{abstract}

\section{Introduction}

Recently, the preventive and therapeutic potential of food and beverages has received increased scientific attention. Large epidemiological surveys have shown a relationship between the consumption of fruit and vegetables and reduced risk of cancer and cardiovascular disease (1), and some of the works even indicate that raw vegetables give the strongest protection (2-4).

An expression like "the French paradox" has appeared, based on the interesting observation that the French have comparable plasma cholesterol levels to the Americans, and comparable fat intakes, but nevertheless a far lower incidence of coronary disease (5). The high French consumption of red wine has

Table 1. Some dietary substances suggested to be associated with decreased risk of disease.

Vitamins (e.g. ascorbic acid, $\alpha$-tocopherol)

Minerals (e.g. selenium, zinc, manganese)

Dietary fibre

Glucosinolates

Indols

Flavonoids

Terpenoids (including carotenoids)

Phytosterols

Proteinase inhibitors

Sulphur compounds from onion and garlic

Helle Margrete Meltzer, Ph.D., Nordic School of Nutrition, School of Medicine, Univ. of Oslo, P.O. Box 1046, Blindern, N-0316 Oslo, Norway.

Karl Egil Malterud, Prof.* Dept. of Pharmacognosy, Institute of Pharmacy, The Univ. of Oslo, PO Box 1068, Blindern, N-0316 Oslo, Norway. Email:k.e.malterud@farmasi.uio.no

*Correspondence been implicated in these differences (6). Others claim that they can be explained by olive oil, or the consumption of garlic. Does red wine, olive oil and garlic have anything in common? (apart from "the good life" which such a consumption surely is an expression of, important in itself for health).

Several components in fruits and vegetables have drawn attention as possible candidates when the effects are to be explained, as illustrated in Table 1. For each of the candidates, there is evidence that they may have an effect. To assess their single and combined effects is an enormous task, which is only at its beginning. This article focuses on the flavonoids, a group of naturally occurring compounds which recently has attracted considerable attention as dietary constituents with potential importance for health (7-9) (Fact column 1).

\section{Chemical structure}

Flavonoids have a common skeleton of diphenylpyranes (C6-C3-C6), i.e. two benzene rings ( $\mathrm{A}$ and $\mathrm{B}$ ) connected by a heterocyclical pyran- or pyron ring (Figure 1). The flavonoids are often hydroxylated in the positions $3,5,7,3^{\prime}, 4^{\prime}$,

\section{FACT COLUMn 1: History}

Flavonoids have been known as plant pigments for more than one hundred years. In periods, their biological effects and importance have been discussed intensively. Around 1940 the opinion was that flavonoids had vitamin properties. In the 1970 s, the flavonoids were suspected of having mutagenic and carcinogenic effect, while in the $80 \mathrm{~s}$ and $90 \mathrm{~s}$, considerable research has been directed towards their activity as antioxidants and radical scavengers, as well as their anti-mutagenic and anti-carcinogenic properties.

In a human context, interest in flavonoids originates from studies by the Nobel laureate Szent-Györgyi and co-workers in the 1930s $(83,84)$, when they reported that a number of substances in vegetables and fruits (different from vitamin C) could heal the capillary fragility (with associated haemorrhage) characteristic of scurvy. For years there was an argument as to whether the flavonoids, often designated as bioflavonoids or vitamin $\mathrm{P}$, had a direct, independent effect on tissue metabolism (especially capillary fragility), or if their role rather was of a synergistic nature.

Around 1950 it was agreed that the flavonoids had physiological significance, but that their most important and possibly single role was their influence on capillary resistance. The effect seemed to be independent of vitamin C. In spite of this, flavonoids were taken off the list of effective drugs by the US Food and Drug Administration in 1962. At this point there were more than 200 flavonoid-containing preparations on the American market.

Interest in the biological effects of flavonoids has increased tremendously the last 15-20 years (85), and several thousand articles have been published on the theme. In addition to the more important effects mentioned in the main article, the are some more exotic ones. Among them are inhibition of tooth decay $(86,87)$, protection against snake venom (88), or effect against dandruff (89)! Several books, such as (90-92) and reviews, e.g. $(21,24,93)$ have been published. 
and 5'. The presence or absence of a hydroxyl group in the 3 position determines the division into the two main subgroups of flavonoids: 3-hydroxyflavonoids (flavonols, flavanonols and catechins) and flavonoids with an unsubstituted 3-position (flavones and flavanones) (Figure 1). The most common flavonoid in food is quercetin, while catechins nutritionally are the most important of the flavonoids in beverages, due to their high concentration in tea. More than 4,000 flavonoids have been described, and the number of characterised substances is continually increasing (10).

From a nutritional point of view, flavonols and flavones are of special interest due to their potential protective role in carcinogenesis, atherosclerosis and thrombosis. Both flavonols and flavones are usually present in our food as glycosides, D-glucose being the most common sugar. Other sugars can be galactose, rhamnose, arabinose, xylose, in addition to glucuronic acid. The preferred binding site for the sugar unit is in the $\mathrm{C} 3$ position, glycosylation in the $\mathrm{C} 7$ position being somewhat less common $(11,12)$. The sugar-free part of the molecule is called the flavonoid aglycone.

Due to the enormous variation in substitution types and substitution patterns, (hydroxylation-, methoxylation-, sulphation- and glycosidation patterns in addition to C-methylation, C-glycosylation and prenylation) more than 1,000 different flavonol and flavone glycosides have been described, and more than 20 million different combinations are theoretically possible (13).

\section{Function in plants}

Numerous functions of flavonoids in plants have been demonstrated or suggested. These include pigmentation (to attract pollinators), protection of the plant from UV light and micro-organisms, defence against grazing animals, regulation of enzyme activity and signal substances for nitrogen-fixating bacteria $(14,15)$. The flavonoids are omnipresent in higher plants. In foods, we find flavonoids as natural colour substances (the anthocyanins, a subgroup of flavonoids, have a strong red, purple or mauve colour and may give a blue colour when combined with other substances in plants; chalcones and aurones are yellow), taste components and as antioxidants (16).

Flavones and flavonols can be pale yellow or creamy coloured. Some colours are only visible to pollinating insects, which can sense UV radiation invisible to humans. Thus they can sense "flavonoid colours" not visible to man.

Figure 1. Flavonoid structures (above) and formulae for some common flavonoids.<smiles>[R]c1c(-c2ccccc2)oc2ccccc2c1=O</smiles>

$\mathrm{R}=\mathrm{H}$ : Flavones $\mathrm{R}=\mathrm{OH}$ : Flavonols<smiles>[R]C1C(=O)c2ccccc2OC1c1ccccc1</smiles>

$\mathrm{R}=\mathrm{H}$ : Flavanones $\mathrm{R}=\mathrm{OH}$ : Flavanonols<smiles>[R]C1Cc2ccccc2OC1c1ccccc1</smiles>

$\mathrm{R}=\mathrm{H}$ : Flavanes $\mathrm{R}=\mathrm{OH}$ : Catechins<smiles>[R]c1cc(-c2oc3cc(O)cc(O)c3c(=O)c2[R])cc([R1])c1O</smiles>

$$
\begin{aligned}
& \mathrm{R}_{1}=\mathrm{OH}, \mathrm{R}_{2}=\mathrm{R}_{3}=\mathrm{H} \text { : Kaempferol } \\
& \mathrm{R}_{1}=\mathrm{R}_{2}=\mathrm{OH}, \mathrm{R}_{3}=\mathrm{H} \text { : Quercetin } \\
& \mathrm{R}_{1}=\mathrm{R}_{2}=\mathrm{R}_{3}=\mathrm{OH} \text { : Myricetin } \\
& \mathrm{R}_{1}=\mathrm{R}_{2}=\mathrm{R}_{3}=\mathrm{H}: \text { Apigenin } \\
& \mathrm{R}_{1}=\mathrm{R}_{3}=\mathrm{H}, \mathrm{R}_{2}=\mathrm{OH} \text { : Luteolin }
\end{aligned}
$$

\section{Presence in foods}

Flavonols and flavones are mainly present in the leaves and outer parts of plants, but small amounts have also been detected in roots $(11,12)$. One exception is onions, where the bulb contains considerable amounts of quercetin 4'-glycosides. We receive approximately $70 \%$ of the flavonoids in the diet from beverages and fruit. Some herbs and spices have high concentrations, and large amounts are also found in some well known medicinal plants. For centuries lay people and medical professionals have used herbs containing flavonoids in attempts to heal inflammations, diabetes, allergies, headaches, the common flu, cancer etc. (13). Propolis, made by bees from plant exudates (usually from buds), is used to protect the hive entrance and is often rich in flavonoids. From old times the peoples of Asia have been drinking green tea as a medicinal remedy because of its presumed pharmacological effects. Green tea is an important source of flavonoids in the East (17).

Our knowledge about the dietary intake of flavonoids is sparse and partly contradictory. In 1976 Kühnau (18) estimated the daily flavonoid intake in the USA to be approximately 1 gram, $100 \mathrm{mg}$ thereof being flavonols and flavones, but these estimates have not been confirmed. Hertog et al. (19) have improved the old analytical methods, and their results are shown in Table 2. Based on the analysis of five common flavonoids, the flavonoid content of the Dutch diet was estimated to be $28 \mathrm{mg} /$ day (as aglycones). In areas with a very high intake of plants and herbs/ spices, the intake of flavonoids is believed to be as high as 2-3 g/day. Many factors influence the flavonoid content of plants, among others the conditions of growth, ripeness and season. Growth beneath glass reduces the levels of flavonoids, and in general, processed foods have $50 \%$ lower concentrations than fresh (20). A subgroup of flavonoids, the isoflavonoids, are mainly found in the Leguminosae, soy beans being an example of a food with a substantial content of isoflavonoids.

\section{Biological effects}

Recently, the antioxidant properties of the flavonoids have become a subject of considerable interest (21-23), but in addition, several other properties have been reported, some of which are shown in Table $3(13,16,24,25)$. Among the effects can be mentioned modulation of enzyme activity, e.g. cyclooxygenase, lipoxygenases, phospholipase A2, hyaluronidase and 5 '-iodothyronine deiodinase. Inhibition of LAR (lens aldose reductase) and of ACE (angiotensin convertase) has also been described. These effects provide a broad potential for medical effects and usage, and in particular, work is presently being conducted with flavonoids and cancer (Fact column 2, p 53). In this paper, however, we will concentrate on the possible impact flavonoids may have on coronary heart disease. In this context, we will discuss the antioxidant properties of flavonoids. 
Table 2. Concentrations of quercetin (Q), kaempferol (K) and myricetin $(\mathrm{M})$ in some foods and beverages (in $\mathrm{mg} / \mathrm{kg}$ for foods, $\mathrm{mg} / \mathrm{L}$ for beverages). Data from Hertog et al $(20,106)$.

\begin{tabular}{llll}
\hline Q & K & $M$
\end{tabular}

\begin{tabular}{lll}
\hline Onions & $347 \pm 63$ & $<2$ \\
Tomatoes & $8 \pm 3.1$ & $<2$ \\
Cauliflower & $<1$ & $<2$ \\
Broccoli & 30 & 72 \\
Kale & 110 & 211 \\
Apples & $36 \pm 19$ & $<2$ \\
Apricots & 25 & $<2$ \\
Pears & $6.4 \pm 3.4$ & $<2$ \\
Grapes (green) & 12 & $<2$ \\
Grapes (blue) & 15 & $<2$
\end{tabular}

Wines

Red Bordeaux

Red Chianti

4.1

16

Red California $\quad 8.8$

White Bordeaux $<0.5$

White Moselle $<0.5$

Fruit juices

Apple

Grape

Tomato

Orange

(commercial)

Orange

(freshly pressed)

2.5

4.4

13

5.7

3.4

Beer (Heineken) $<0.5$

Chocolate milk 1.3

Tea*

Lipton 25

$\begin{array}{ll}\text { English Breakfast } & 11 \\ \text { Green Japanese } & 23\end{array}$

\begin{abstract}
* Made from tea bags ( $5 \mathrm{~g}$ ) or the equivalent. The seasonal variations were considerable for leafy vegetables such as lettuce $(1.9-30 \mathrm{mg} / \mathrm{kg}$ of quercetin), endives $(15-95 \mathrm{mg} / \mathrm{kg}$ of kaempferol) and leek (11-56 $\mathrm{mg} / \mathrm{kg}$ of kaempferol). For cabbage, the variations were smaller.
\end{abstract}

\section{Coronary heart disease}

The composition of the diet influences the risk for developing coronary heart disease, and not least "the French paradox" and other phenomena show that the influence is not limited to the effect of saturated fat and cholesterol (5). The mechanisms underlying the development of atherosclerosis are not completely understood, but it is generally believed that early in the process, macrophages in the artery walls take up modified LDL (low density lipoprotein) from plasma by a route independent of the LDL receptor, and the receptor involved (often called the scavenger receptor) only recognises modified, e.g. oxidised LDL. We know that native LDL can be modified by all the most important types of cells in the vasculature, including endothelial cells, smooth muscle cells and macrophages.
There is some evidence that cellularly produced 15-lipoxygenase may be involved in the process (49).

Oxidised LDL has strong atherogenic properties, e.g. by chemoattraction of monocytes and by the macrophages being inhibited from migrating back into the plasma. This leads to an accumulation of macrophages, saturated with cholesteryl esters, in intima. Gradually the macrophages are transformed to foam cells, which may then develop into fatty streaks. A fatty streak can further develop into fibrotic plaques, which become calcified and lead to reduction of the lumen (26).

Oxidised LDL is also cytotoxic, and may harm endothelial cells. This damage is accompanied by release of factors stimulating platelet aggregation and early growth of thrombosis. The combination of thrombogenesis and reduced intraluminal volume may lead to infarction.

Thus, substances protecting against the oxidation of LDL are of considerable interest in the prevention and treatment of coronary heart disease (27). In addition, substances with antithrombotic properties will be of interest. $\alpha$-Tocopherol (vitamin E), retinyl stearate, $\gamma$ - tocopherol and $\beta$ carotene have been reckoned among the most important antioxidants. All are fatsoluble. It is, however, well known that the content of antioxidants in an LDL particle of a healthy adult can vary widely, and it is tempting to speculate that the dietary content may have an impact. The cytosolic levels of antioxidants also influence the oxidation of LDL. Best known among these is ascorbic acid (vitamin C), which can react directly with superoxide and hydroxyl radicals and in vitro can reduce the tocopheroxyl radical back to $\alpha$ tocopherol.

To our knowledge, no attempts have been made to quantify the flavonoid content of human LDL.

\section{Flavonoids as antioxidants}

Many flavonoids are strong antioxidants; for a review, see, e.g. (21). Several in vitro studies have shown flavonoids to have stronger antioxidant properties in some assay systems than $\alpha$-tocopherol. Usually, the optimal antioxidant activity of flavonoids is related to neighbouring phenolic hydroxyl groups (usually in the 3' - and 4'position), a double bond between $\mathrm{C} 2$ and $\mathrm{C} 3$ in conjugation with a carbonyl group at $\mathrm{C} 4$, and hydroxyl groups at $\mathrm{C} 3$ and $\mathrm{C} 5$ (28). Flavonols combining these properties, such as quercetin, can scavenge radicals such as superoxide, hydroxyl, alkoxyl and peroxyl. However, some flavonoids are strong antioxidants and radical scavengers without having this structure $(29,30)$.
It is well known that flavonoids seem to have vitamin $\mathrm{C}$ sparing effects $(31,32)$, and it has been assumed that this is related to their antioxidant properties. "Vitamin C2" was once suggested as a name for some flavonoids, but this was never generally accepted $(31,33)$. Moreover, recent data (34) indicate that the vitamin C sparing effect is not as easily explained as earlier believed.

\section{$L D L$}

As previously mentioned, data have gradually accumulated indicating that oxidation of LDL is an important factor in the development of atherosclerosis (reviews, see (35-37)). Atherogenesis is, however, a very complex process (38).

In in vitro experiments, flavonoids inhibit the oxidation of LDL triggered by cellular (e.g. macrophages) as well as noncellular factors (e.g. copper ions) (39-47). Scavenging of free radicals participating in oxidative processes may thus be an explanation for some of the observed effects of flavonoids. Other mechanisms, such as protection of $\alpha$-tocopherol, have also been suggested. In addition, quercetin reduces the cytotoxic effects of oxidised LDL $(46,48)$. The mechanism underlying this effect is not known.

Because 15-lipoxygenase has been suggested to participate in the oxidation of LDL (49), it is of particular interest that several flavonoids inhibit this enzyme $(50,51)$.

Frankel et al. have shown that phenols extracted from red wine inhibited $\mathrm{Cu}$ catalysed oxidation of human LDL ex vivo (52). This has been corroborated by other studies $(53,54)$.

Recent experiments show that soybean isoflavonoids given to rhesus monkeys reduce $L D L$ levels and increase the levels of HDL (high density lipoprotein) in plasma, and thus would be expected to have a beneficial effect in connection with coronary heart disease (107). So far, it is not known whether this effect also applies to humans.

\section{Platelet aggregation}

Since the 1950 s it has been known that flavonoids may have an antithrombotic effect and inhibit platelet aggregation (55). The effect is well documented both in vitro and in vivo in animal experiments, as well as ex vivo in humans (56). The mechanisms behind the antiaggregatory effect seem complex. In many cases, inhibition of cyclic AMP phosphodiesterase, resulting in increased cAMP levels, seems to be important (57), but this is apparently not the case for the antiaggregatory flavonoids in green tea (58).

A number of other mechanisms have 
been suggested: an influence on the metabolism of arachidonic acid (with reduction in thromboxane levels) $(59,60)$ - receptor antagonism to tromboxane receptors have also been reported (61), as well as an increase in the levels of prostacyclin (62). Many flavonoids are strong inhibitors of lipoxygenases, but have differing effect on cyclooxygenase (63, 64). Reduction of calcium levels (60), inhibition of "platelet activating factor" (58), scavenging of free radicals (65) and reduced liberation of proaggregatory enzymes (66) have been observed. Apparently, the antiaggregatory effects of flavonoids are due to several more or less separate mechanisms.

One would expect the substantial effect of flavonoids on arachidonic acid metabolism to result in antiinflammatory properties, and this has indeed been demonstrated, mainly in animal experiments in vivo, but also in experiments with human cells in vitro (67-71). In this case, as well, several mechanisms seem to be involved. The literature is reviewed in, e.g. $(24,72)$.

In summary, the antiinflammatory, antiaggregatory and antioxidative/radical scavenging effects of flavonoids are well documented in in vitro systems, and the results point at several, partly independent, mechanisms. One can not disregard the possibility that still other effects may be of importance; inhibition of xanthin oxidase (produces superoxide radicals), myeloperoxidase (produces hypochlorite, another prooxidant) and angiotensin convertase (gives angiotensin II, which increases blood pressure) has also been reported for the flavonoids.

\section{Therapeutic use}

Medical use of plants rich in flavonoids goes back to ancient times. This practice was probably based on experience, and only lately has the use of flavonoids and flavonoid-containing preparations been based on rational biochemical knowledge.

The ability to counteract capillary permeability was the first biological effect shown for flavonoids. A number of pharmaceuticals, both with natural flavonoids and semisynthetic derivatives, take advantage of this effect, as shown in several clinical studies $(73,74)$.

A flavonoid with an unusual structure, silybin (from the thistle Silybum marianum, "Mariendistel" - an ancient medical plant from central Europe (75)), has hepatoprotective effect and is included in many pharmaceuticals. Its clinical effect is well documented (review, see (76)).

Another flavonoid, catechin (cyanidanol), also showed promising clinical activity against hepatic disease, but turned out to give serious side effects, probably of

Table 3. Some biological effects reported for flavonoids (based mainly on in vitro experiments) ${ }^{\#}$.

* Antioxidant effect / radical scavenging

* Immunomodulating and antiinflammatory effects

- probably mostly due to modulation of arachidonic acid metabolism: Phospholipase A2 inhibition

Cyclooxygenase inhibition or activation

Lipoxygenase (5-, 12-, 15-) inhibition

* Modulation of other enzyme activities (usually inhibition), e.g.:

Lens aldose reductase (LAR)

Xanthin oxidase

5'-Iodothyronin deiodinase

Angiotensin convertase (ACE)

Cyclic AMP phosphodiesterase

* Antiasthmatic and antiallergic effects

* Antiviral, antibacterial and antifungal effects

* Oestrogenic activity

* Effects on mutagenesis and carcinogenesis

* Hepatoprotective effects

* Effect on blood vessels; counteraction of vascular permeability

\# Many of the activities listed above may be correlated; thus, hepatoprotective effects may be due to radical scavenging, antioxidant effects may (in some cases) be due to xanthin oxidase inhibition, and antiasthmatic effects may be due to inhibition of 5-lipoxygenase.

\section{Fact COlumn 2: Flavonoids and Cancer}

Several natural substances and natural substance-derived preparations are used in the treatment of cancer - Vinca alkaloids, etoposid and adriamycin are prominent examples. Flavonoids have also been studied in this connection. Flavone acetic acid, mentioned in the main article, once seemed very promising.

Many flavonoids have been reported to have cytostatical effect in various in vitro systems. These have, however, seldom translated into clinically relevant effects (100). Currently, the flavonoids draw considerable attention because they seem to be able to regulate certain processes important in the development of cancer. Examples of this are antipromotor activity, antiinvasive effect, and inhibition of enzymes like protein tyrosine kinase, TPA-dependent ornithin decarboxylase and DNA topoisomerase. Recently, a synergistic effect between fluorouracil and the flavonoid quercetin has been reported (101), although only in vitro.

Many animal studies have shown that isoflavonoids from soybeans (especially genistein) may have a protective effect against several forms of cancer (breast, colon, skin) (121). This has been related to the oestrogenic effect of isoflavonoids, and several biochemical mechanisms have been discussed (122).

Several flavonoids have antimutagenic effect (for reviews, see ref. 102,103). Although there are studies showing some flavonoids to have mutagenic activity in
Ames test and other assay systems, very few results indicate that flavonoids have carcinogenic effect. In an early article, quercetin was claimed to induce cancer in rats (104), but this has not been confirmed generally by later work. Rather recently, however, it has been shown (123) that extremely large doses of quercetin (4\% of the diet) over a long period of time ( 2 years) induced an increased frequency of kidney cancer in male rats (but not female rats). At lower dosages $(1 \%$ or less) or shorter exposure time (maximum 15 months), there was no significant change in cancer incidence. Some of the methods used in this investigation have, however, been debated (124).

Summarising, the majority of researchers in this field seem to hold the view that the anticancerogenic effects of flavonoids are more important than the procarcinogenic ones $(124,125)$. For further references in this field, see, e.g. (126)

From in vitro data and biochemical knowledge, it appears that the flavonoids may be regarded as dietary constituents which may have beneficial effect (although of a preventive and not a curative nature) in relation to cancer. It should, however, be mentioned that Hertog et al. $(82,105)$, did not find any correlation between flavonoid intake and reduced incidence of cancer, in contrast to what they found for coronary heart disease $(7,82)$. Thus it is too early to say if the many interesting in vitro results will turn out to be of clinical importance. 


\section{FaCt COLUMn 3: Side EFfeCtS}

By and large, flavonoids are relatively nontoxic to higher animals (94-96,114), and seem to be devoid of teratogenic effects (97). As long as the diet is the sole source of flavonoids, the risk of becoming intoxicated seems small. Clinical trials with large doses of the flavonoid catechin (cyanidanol) have, however, showed serious side effects, probably due to immunological reactions $(98,99)$. The dosages in these cases were more than 1 gram/day. The acute $\mathrm{LD}_{50}$ for flavonoids tested in animal experiments normally seems to be above $1 \mathrm{gram} / \mathrm{kg}$ body weight. The mutagenic effect shown for a number of flavonoids in Ames test seems to be of less relevance in a cancer context than the antimutagenic effect shown for flavonoids (see Fact column 2).

Dermatitis induced by flavonoids has been reported. In several of these reports raw extracts of plants were employed, and there is no direct evidence for flavonoids being the triggering factor. Some articles, however, describe tests using pure substances $(115,116)$, and here it appears that certain flavonoids can produce dermatological reactions, although the large majority are inactive.

Propolis, well known for its allergic skin reactions (117), is normally rich in flavonoids, but other substances seem to be responsible for the allergy $(118,119)$.

Some isoflavonoids are oestrogens. Their activity is relatively low, and consumption of soy beans, a rich source of isoflavonoids, does not seem to have adverse oestrogenic effects in humans. It has long been known that sheep grazing on isoflavonoid-rich clover species get hormone balance disturbances, and recently it has been shown that coumestrol, the most active isoflavonoid oestrogen, (but only found in very small amounts in soy beans), disturbs oestrus in female mice and produces abnormal sexual behaviour in male mice (120). immunological nature (Fact column 3).

Preparations from Crataegus (hawthorn), containing oligomeric flavonoids as their (putative) main pharmacologically active ingredients, are used to treat mild heart insufficiency. A Japanese multicenter study testing such a product showed significant improvement compared to a placebo group (78). Studies designed to reveal the mechanisms of Crataegus preparations have recently been reported, e.g. (108-110). Crataegusbased pharmaceuticals can interact with digitalis; thus such preparations should not be administered at the same time.

Pharmaceuticals based on extracts from Ginkgo biloba, an ancient Chinese medicine, have gained substantial use in large parts of Europe the last 10-20 years. In Germany alone 4.2 million prescriptions with such preparations were dispatched in 1990, representing a market value of 263 million DM (79). Usually, partially purified extracts of the plant with a specified content of terpenoids and flavonoids, regarded as the main effective ingredients of the plant, are employed. A number of clinical studies have been performed testing the effect of Ginkgo preparations against age-related cerebral insufficiency, and a meta-analysis of some of these studies showed a clear clinical effect (80).

However, for many of the claimed effects of flavonoids, effects that are seemingly in accordance with claims from folk medicine and results from in vitro and animal experiments, clinical data are lacking. So far, acceptable clinical intervention studies testing the effects of flavonoids against atherosclerotic and thrombotic disease have not been conducted. In the cases where clinical trials have been conducted, they have often not been able to confirm the promising results from in vitro and animal experiments. Flavone acetic acid, a synthetic flavonoid, is an example of this: This compound was chosen by the Cancer Research Campaign (UK) to a phase I, and later a phase II clinical trial. Both in vitro and animal experiments showed the antitumor activity of this compound to be substantial. But only minimal activity could be demonstrated in humans! The process was reviewed in an article with the title: "Flavone acetic acid - from laboratory to clinic and back" (81).

Bioactive compounds from natural sources have often had a disadvantage compared to their synthetic relatives: They are difficult to give effective patent protection. Because of this they have to some extent been regarded as economically uninteresting to the pharmaceutical industry. As flavonoids are tested in clinical trials, they apparently show another handicap: They are highly sensitive to their chemical surroundings. Due to this, well established results may be difficult to reproduce in new experimental settings. This may complicate the therapeutical use of flavonoids.

\section{Epidemiological studies}

Recently, results from several epidemiological studies have been published, including relative precise estimates of the intake of flavonoids $(7,82,111,112)$. Much of this work comes from the Netherlands, and was initiated by a workshop held in
Wageningen in 1990 with the title "Nonnutritive anticarcinogens in foods". Thanks to multidisiplinary co-operation between chemists, nutritionists and epidemiologists, methods were developed for analyses of important food flavonoids. Later, the content in the most relevant Dutch food items were analysed and the Dutch dietary intake was estimated, based on the dietary data. Further, the results were attached to the Seven Countries Study which started in the 1960s.

Results from the food analyses are shown in Table 2. The Zutphen study (7) comprised 805 men from the town Zutphen in Holland being between 65 and 84 years of age when the study started in 1985. The average flavonoid intake (estimated as the sum of the five most important flavonoid aglycones) was $26 \mathrm{mg} /$ day. Most of the flavonoids $(61 \%)$ came from tea, $38 \%$ from vegetables and fruit (mainly onions, kale, endives and apples). The intake was related to the risk of developing cancer and coronary heart disease the following five years. In this period, 43 men died from coronary heart disease while 38 men had myocardial infarction. The flavonoid intake was inversely related to coronary heart mortality ( $P$ for trend=0.003), while the correlation to the incidence of a first infarction was much weaker after adjustment for known risk factors as age, body mass index, smoking, serum cholesterol, blood pressure, physical activity, consumption of coffee, and further for the intake of energy, vitamin $C$, vitamin $E, \beta$-carotene and dietary fibre $(\mathrm{P}=0.15)$. Coronary heart mortality was reduced by more than $50 \%$ in the group belonging to the upper tertile compared to the lowest tertile of flavonoid intake (Table 4). The flavonoid intake was not related to cancer incidence or mortality.

As a first attempt to include the flavonoids in the classical epidemiological cause-effect models for coronary heart mortality, the Dutch group estimated the flavonoid intake around 1960 for the 16 cohorts being part of the Seven Countries Study (82). The average flavonoid intake was inversely correlated to coronary heart mortality in the cohort after 25 years of follow-up, and explained $25 \%$ of the variance. When adjustments were made for other risk factors, saturated fat explained $73 \%$ of the variance, smoking $9 \%$, while flavonoids explained $8 \%$, independent of the intake of the vitamins E, C and alcohol. This study can easily be criticised, e.g. since all estimates were far more uncertain than in the Zutphen study, but nevertheless the results can be an indication of flavonoids being at least a factor to be controlled for in future epidemiological studies. 
The Zutphen Study results have recently found support in a publication from Finland (111). Here, 5133 men and women between 30 and 69 years, with no signs of coronary disease at start, were followed for 26 years. The flavonoid intake was estimated on the basis of dietary reports at the start of the study, and the flavonoid values from the Dutch food item analysis. The intake was far below the Dutch: only $3.4 \mathrm{mg} /$ day as a median, with a range from 0 to $41.4 \mathrm{mg}$. $64 \%$ of the flavonoids came from onions and apples. During the study period, 473 persons died of coronary disease. There was a significant inverse correlation between flavonoid intake and both total and coronary mortality among females, when corrected for age, smoking, serum cholesterol, blood pressure and body mass index. Among the men, the trend was the same, but significant only for total mortality.

The latest of the hitherto published epidemiological studies on dietary flavonoids also comes from Zutphen (112). In this work, 552 men between 50 and 69 years of age were followed in a prospective study investigating the relationship between flavonoid intake and stroke. After correction for confounders (including antioxidant vitamins) it was found that the quartile with the highest flavonoid intake (more than $28.6 \mathrm{mg}$ /day) had significantly fewer cases of stroke than the quartile with the lowest flavonoid intake (less than $18.3 \mathrm{mg} / \mathrm{d}$ ) (RR 0.27 ; $95 \%$ confidence interval $0.11-0.70 ; \mathrm{P}$ for trend $0.004)$. Tea, being the main source of flavonoids in the investigation, gave similar results, while the reduction in stroke associated with increased intake of $\beta$-carotene and vitamin $C$ was not significant. In fact, vitamin E seemed to have a positive correlation with the total amount of strokes, but this correlation was not statistically significant.

\section{Evaluation of dietary flavonoids is problematical}

1 . Hitherto, it has been assumed that most flavonoids are broken down, to a larger or smaller degree, by intestinal bacteria, or that they undergo major structural changes in the gastrointestinal tract. Possibly, completely different metabolites are present in the body after absorption than those ingested. Thus, nutritional consequences of the flavonoids are not necessarily a result of the flavonoids in themselves, but of enteral or postabsorptive interactions and degradation products. For this reason, one has to distinguish sharply between experiments where flavonoids are given orally and by other routes, and also between in vivo and
Table 4. Some results from the Zutphen study (7). In this study, diet, mortality and CHD incidence was studied in 805 men aged 65 to 84 years. The study started in 1985 and lasted five years. RR is adjusted for age, dietary factors, physical activity, body mass index, smoking, total serum cholesterol, HDL cholesterol, and systolic blood pressure. Abbreviations: $\mathbf{R R}=$ relative risk, $\mathbf{C H D}=$ coronary heart disease, $\mathrm{MI}=$ myocardial infarction.

\begin{tabular}{|c|c|c|c|}
\hline End point & Variable & $\mathrm{RR}$ & P for trend \\
\hline CHD mortality & $\begin{array}{l}\text { Flavonoid intake: } \\
1-19 \mathrm{mg} / \mathrm{d} \\
19.1-29.9 \mathrm{mg} / \mathrm{d} \\
>29.9 \mathrm{mg} / \mathrm{d}\end{array}$ & $\begin{array}{l}1 \\
0.32 \\
0.32\end{array}$ & 0.003 \\
\hline $\begin{array}{l}\text { Incidence of fatal } \\
\text { and non-fatal first MI }\end{array}$ & $\begin{array}{l}\text { Flavonoid intake: } \\
1-19 \mathrm{mg} / \mathrm{d} \\
19.1-29-9 \mathrm{mg} / \mathrm{d} \\
>29.9 \mathrm{mg} / \mathrm{d}\end{array}$ & $\begin{array}{l}1 \\
0.89 \\
0.52\end{array}$ & 0.15 \\
\hline Total mortality & $\begin{array}{l}\text { Flavonoid intake: } \\
1-19 \mathrm{mg} / \mathrm{d} \\
19.1-29-9 \mathrm{mg} / \mathrm{d} \\
>29.9 \mathrm{mg} / \mathrm{d}\end{array}$ & $\begin{array}{l}1 \\
0.75 \\
0.72\end{array}$ & 0.084 \\
\hline CHD mortality & $\begin{array}{l}\text { Tea intake*: } \\
0-250 \mathrm{ml} / \mathrm{d} \\
251-500 \mathrm{ml} / \mathrm{d} \\
>500 \mathrm{ml} / \mathrm{d}\end{array}$ & $\begin{array}{l}1 \\
0.38 \\
0.45\end{array}$ & 0.024 \\
\hline CHD mortality & $\begin{array}{l}\text { Apple intake: } \\
0-18 \mathrm{~g} / \mathrm{d} \\
19-110 \mathrm{~g} / \mathrm{d} \\
>110 \mathrm{~g} / \mathrm{d}\end{array}$ & $\begin{array}{l}1 \\
0.90 \\
0.51\end{array}$ & 0.12 \\
\hline
\end{tabular}

* Correlation between flavonoid and tea consumption: $r=0.83$.

in vitro studies. So far we cannot disregard the possibility that the health impact of flavonoids primarily is a result of what happens in the intestine, e.g. through their influence on our immune system or intestinal bacteria.

2. Flavonoids usually co-occur with other active substances in foods, like vitamin $C$, and one has to consider that eventual effects of flavonoids are dependent on interactions with other dietary components.

3. The effects of flavonoids seem to be mainly preventive, and it is much more difficult to study (unknown) effects of prevention than treatment.

4. Flavonoids seem to have a broad spectrum of effects, and this may make rational applications more difficult, even if a broad-spectrum effect can be therapeutically beneficial. Furthermore, there does not seem to be any effect for which the flavonoids constitute the only responsible agent.

5. The metabolism and pharmacokinetics of flavonoids in humans is not very well understood. Flavonoids can be metabolised and degraded by the intestinal microflora, but they can also be metabolised hepatically and even enter the enterohepatical circuit. In flavonoid research, high priority is given to finding out absorbed in humans (22), and studies on this theme are presently performed by several research groups, e.g. $(127,128)$. Some results concerning the biological activity of flavonoid metabolites have recently been published $(45,113)$, but a lot still remains to be done in this field.

6. A standard method of approach to assess the function of dietary components has been to compose diets without the substance to be studied, follow an eventual modulation of metabolic processes, and then follow these processes when the substance is reintroduced (depletion/ repletion studies). It is virtually impossible to compose a diet free of flavonoids but still adequate when it comes to regular nutrients. At the same time, such a diet has to be acceptable to the human subjects. These aspects make human experiments difficult to design. The emerging results from epidemiological and clinical studies indicate that these problems may be overcome, even though results may be difficult to interpret. The evidence obtained from clinical and epidemiological studies so far seem to indicate that flavonoids may, indeed, possess important biological activity. how and to what degree flavonoids are 


\section{Conclusion}

Although no flavonoid-specific biological functions have been demonstrated so far, a growing amount of evidence indicates that the intake of flavonoids may be of considerable importance to health. A multitude of promising in vitro experiments have been carried out, but relatively few clinical trials or epidemiological studies. As natural substances with limited patentability, they have attracted only moderate interest from the pharmaceutical industry, and this has limited the total research effort in the field. Recent epidemiological studies indicate that the flavonoids should be taken into consideration, and controlled for, in epidemiological studies of coronary heart disease. The assessment of the impact of the flavonoids on human health is difficult because of the high complexity of the antioxidant system of the body, and the picture is complicated further by the flavonoids also having mechanisms of action which are largely independent of the antioxidant system.

\section{References}

1. Steinmetz KA, Potter JD: Vegetables, fruit, and cancer. I. Epidemiology. Cancer Causes Contr 1991;2:325-57.

2. Steinmetz KA, Potter JD: Vegetables, fruit, and cancer. II. Mechanisms. Cancer Causes Contr 1991;2:427-42.

3. Dragsted LO, Strube M, Larsen JC: Cancerprotective factors in fruits and vegetables: Biochemical and biological background. Pharmacol Toxicol 1993;72 (Suppl 1):116-35.

4. Willett WC:Diet and health: What should we eat? Science 1994;264:532-7.

5. Renaud S, de Lorgeril M: Wine, alcohol, platelets and the French paradox for coronary heart disease. Lancet 1992;339:1523-6.

6. Kinsella JE, Frankel E, German B, Kanner J: Possible mechanisms for the protective role of antioxidants in wine and plant foods. Food Technol 1993; April:85-9.

7. Hertog MGL, Feskens EJM, Hollmann PC, Katan MB, Kromhout D: Dietary antioxidant flavonoids and risk of coronary heart disease: the Zutphen elderly study. Lancet $1993 ; 342: 1007-11$.

8. Hertog MGL: Les flavonoïdes dans le the, le vin rouge et les oignons protègent-ils contre les maladies cardiovasculaires et le cancer? Polyphenols Actualités 1995;13:17-9.

9. Wadworth SM, Lynch S: Dietary flavonoids in atherosclerosis prevention. Ann Pharmacother 1995;29;627-8.

10. Markham KR: Flavones, flavonols and their glycosides. In Harborne JB, ed. Methods in Plant Biochemistry, Vol. 1: Plant Phenolics. London: Academic Press, 1989: 197-235.

11. Herrmann K: Flavonols and flavones in food plants: a review. J Food Technol 1976;32:47-52.

12. Herrmann $\mathrm{K}$ : On the occurence of flavonol and flavone glycosides in vegetables. Z Lebensm Untersuch Forsch 1988;186:1-5.

13. Havsteen B: Flavonoids, a class of natural products of high pharmacological potency, Biochem Pharmacol 1983;32:1141-8.

14. McClure J: Physiology and functions of flavonoids. In: Harborne JB, Mabry TJ, Mabry H, eds. The Flavonoids. London: Chapman \& Hall, 1975:970-1055.

15. Harborne JB. Grayer RJ: Flavonoids and insects. In: Harborne JB, ed. The Flavonoids - Advances in Research since 1986. London: Chapman \& Hall, 1994:589-618.
16. Singleton VL: Flavonoids. Adv Food Res 1981;27:149-242.

17. Wang ZY, Das M, Bickers DR, Mukhtar H: Interaction of epicatechins derived from green tea with rat hepatic cytochrome P-450. Drug Metab Disp 1988;16;98-103.

18. Kühnau J: The flavonoids: a class of semi-essential food components: their role in human nutrition. World Rev Nutr Diet 1976;24:117-91.

19. Hertog MGL, Hollman PCH, Venema DP Optimization of a quantitative HPLC determination of potentially anticarcinogenic flavonoids in vegetables and fruits. J Agr Food Chem 1992;40:1591-8.

20. Hertog MGL, Hollman PCH, Katan MB: Conten of potentially anticarcinogenic flavonoids of 28 vegetables and 9 fruits commonly consumed in the Netherlands. JAgr Food Chem 1992;40:2379-83

21. Kandaswami C, Middleton E: Free radical scavenging and antioxidant activity of plan flavonoids. Adv Exp Med Biol 1994;366:351-76.

22. Rice-Evans CA, Miller NJ, Bolwell PG, Bramley PM, Pridham JB. The relative antioxidant activities of plant-derived polyphenolic flavonoids. Free Rad Res 1995; 22:373-83.

23. Cotelle N, Bernier J-L, Catteau JP, Pommery J, Wallet J-C, Gaydou W: Antioxidant properties of hydroxy-flavones. Free Rad Biol Med 1996; 20:35-43.

24. Middleton E, Kandaswami C: Effects of flavonoids on immune and inflammatory cell functions. Biochem Pharmacol 1992;43:1167-79.

25. Middleton E, Kandaswami C: The impact of plant flavonoids on mammalian biology: Implications for immunity, inflammation and cancer. In: Harborne JB, ed. The Flavonoids - Advances in Research since 1986. London: Chapman \& Hall, 1994: 619-52.

26. Esterbauer H, Waeg G, Puhl H: Lipid peroxidation and its role in atherosclerosis. $\mathrm{Br}$ Med Bull 1993;49:566-76.

27. Gey KF, Moser UK, Jordan P, Stähelin HB, Eichholzer M, Lüdin E: Increased risk of cardiovascular disease at suboptimal concentrations of essential antioxidants: an epidemiological update with special attention to carotene and vitamin C. Am J Clin Nutr, Suppl 1993;57:787S-97S.

28. Bors W, Heller W, Michel C, Saran M: Flavonoids as antioxidants: Determination of radicalscavenging efficiencies. Methods Enzymol 1990;186:343-55.

29. Malterud KE, Oanh DH, Sund RB. C-Methylated dihydrochalcones from Myrica gale L.: Effects as antioxidants and scavengers of 1,1-diphenyl-2 picrylhydrazyl. Pharmacol Toxicol 1996;78:111-6.

30. Mathiesen L, Malterud KE, Sund RB. Antioxidant activity of fruit exudate and C-methylated dihydrochalcones from Myrica gale L. Planta Med 1995;61:515-8

31. Cotereau H, Gabe M, Géro E, Parrot J-L: Influence of vitamin $P$ (vitamin $C_{2}$ ) upon the amount of ascorbic acid in the organs of the guinea pig. Nature 1948;161:557-8.

32. Clemetson $\mathrm{CAB}$, Andersen L: Plant polyphenols as antioxidants for ascorbic acid. Ann NY Acad Sci 1966;136:341-76.

33. Cazave J-M, Hayaux du Tilly-Achard M, Parrot JL: The $\mathrm{C}_{2}$ factor. In: Farkas L, Gábor M, Kállay F, eds. Flavonoids and bioflavonoids - Current research trends. Amsterdam: Elsevier, 1977:43943.

34. Bors W, Michel C, Schikora S: Interaction of flavonoids with ascorbate and determination of their univalent redox potentials: A pulse radiolysis study. Free Rad Biol Med 1995; 19:45-52.

35. Steinberg D, Parthasarathy S, Carew T, Khoo JC, Witztum JL: Beyond cholesterol: Modifiers of low density lipoprotein that increase its atherogenicity. New Engl J Med 1989,315:91524.

36. Hoff HF, O'Neil JA: Oxidation of LDL: Role in atherogenesis. Klin Wochenschr 1991;69: 10328

37. Parthasarathy S, Rankin SM: Role of oxidized low density lipoprotein in atherogenesis. Progr Lipid Res 1992;31:127-43.

38. Ross R: The pathogenesis of atherosclerosis: A perspective for the 1990s. Nature 1993;362:801-9.

39. Ray BR, Davisson EO, Crespi HL: Experiments on the degradation of lipoproteins from serum. $\mathrm{J}$ Phys Chem 1954;58:841-6.

40. Jessup W, Rankin SM, de Whalley C, Hoult JRS Scott, J, Leake DS: $\alpha$-Tocopherol consumption during low-density-lipoprotein oxidation. Biochem J 1990;265:399-405.

41. de Whalley CV, Rankin SM, Hoult JRS, Jessup W, Leake DS: Flavonoids inhibit the oxidative modification of low density lipoproteins by macrophages. Biochem Pharmacol 1990;39: 1743-50.

42. Mangiapane H, Thomson J, Salter A, Brown S, Bell GD, White DA: The inhibition of the oxidation of low density lipoprotein by (+)catechin, a naturally occurring flavonoid. Biochem Pharmacol 1992;43:445-50.

43. Miura S, Watanabe J, Tomita T, Sano M, Tomita I: The inhibitory effects of tea polyphenols (flavan3 -ol derivatives) on $\mathrm{Cu} 2+$ mediated oxidative modification of low density lipoprotein. Biol Pharm Bull 1994;17:1567-72.

44. Miura S, Watanabe J, Sano M, Tomita T, Osawa T, Hara Y et al.: Effects of various natural antioxidants on the $\mathrm{Cu} 2+$-mediated oxidative modification of low density lipoprotein. Biol Pharm Bull 1995; 18:1-4

45. Manach C, Morand C, Texier O, Favier M-L, Agullo G, Demigné $C$ et al.: Quercetin metabolites in plasma of rats fed diets containing rutin or quercetin. J Nutr 1995;125: 1911-22.

46. Nègre-Salvayre $A$, Mabile L, Delchambre $J$, Salvayre R: $\alpha$-Tocopherol, ascorbic acid, and rutin inhibit synergistically the copper-promoted LDL oxidation and the cytotoxicity of oxidized LDL to cultured endothelial cells. Biol Trace Elem Res 1995;47:81-91.

47. Mathiesen L, Malterud KE, Nenseter MS, Sund RB: Inhibition of low density lipoprotein oxidation by myrigalone $\mathrm{B}$, a naturally occurring flavonoid. Pharmacol Toxicol 1996; 78:143-6.

48. Nègre-Salvayre A, Salvayre R: Quercetin prevents the cytotoxicity of oxidised low-density lipoproteins by macrophages. Free Rad Biol Med 1992;12:101-6.

49. Folcík VA Nivar-Aristy RA, Krajewski LP, Cathcart MK: Lipoxygenase contributes to the oxidation of lipids in human atherosclerotic lesions. J Clin Invest 1995;96:504-10.

50. Baumann J, Bruchhausen F, Wurm G: Flavonoids and related compounds as inhibitors of arachidonic acid peroxidation. Prostaglandins 1980;20:627-39.

51. Lyckander IM, Malterud KE: Lipophilic flavonoids from Orthosiphon spicatus as inhibitors of 15-lipoxygenase. Acta Pharm Nord 1992;4:159-66.

52. Frankel EN, Kanner J, German JB, Parks E, Kinsella JE: Inhibition of oxidation of human lowdensity lipoprotein by phenolic substances in red wine. Lancet 1993;43:454-7.

53. Fuhrman B, Lavy A, Aviram M: Consumption of red wine with meals reduces the susceptibility of human plasma and low-density lipoprotein to lipid peroxidation. Am J Clin Nutr 1995;61:549-54.

54. Whitehead TP, Robinson D, Allaway S, Syms J, Hale A. Effect of red wine ingestion on the antioxidant capacity of serum. Clin Chem 1995;41:32-5.

55. Naegeli T, Matis P: Die Bedeutung einiger Vitamine für die Behandlung der Thromboembolie. Int Z Vitaminforsch 1957;27:324-33.

56. Pulliero G, Montin S, Bettini V, Martino R, Mogno C, Lo Castro G: Ex vivo study of the inhibitory effects of Vaccinium myrtillus anthocyanosides on human platelet aggregation. Fitoterapia 1989; 60:69-75

57. Beretz A, Cazenave JP: Old and new natural products as the source of modern antithrombotic drugs. Planta Med 1991;57 (suppl.): S68-72.

58. Sagesaka-Mitane Y, Miwa M, Okada S: Platelet aggregation inhibitors in hot water extract of green tea. Chem Pharm Bull 1990;38:790-3

59. Chang W-C, Hsu F-L: Inhibition of platelet aggregation and arachidonate metabolism in platelets by procyanidins. Prostagl Leukotr Essent Fatty Acids 1989;38:181-8.

60. Kimura Y, Okuda T, Okuda H: Effects of flavonoids from licorice roots (Glycyrrhiza inflata Bat.) on arachidonic acid metabolism and aggregation in human platelets. Phytother Res 1993; 7:341-7. 
61. McNicol A: The effects of genistein on platelet function are due to thromboxane receptor antagonism rather than inhibition of tyrosine kinase. Prostagl Leukotr Essent Fatty Acids 1993;48:379-84.

62. Morazzoni P, Magistretti MJ: Effects of Vaccinium myrtillus anthocyanosides on prostacyclin-like activity in rat arterial tissue. Fitoterapia 1986:57:11-4.

63. Moroney MA, Alcaraz MJ, Forder RA, Carey F, Hoult JRS: Selectivity of neutrophil 5-lipoxygenase and cyclo-oxygenase inhibition by an antiinflammatory flavonoid glycoside and related aglycone flavonoids. J Pharm Pharmacol 1988;40:787-92.

64. Laughton MJ, Evans PJ, Moroney MA, Hoult JRS, Halliwell B: Inhibition of mammalian 5lipoxygenase and cyclo-oxygenase by flavonoids and phenolic dietary additives: Relationship to antioxidant activity and to iron-reducing ability. Biochem Pharmacol 1991; 42:1673-81.

65. Gryglewski RJ, Korbut R, Robak J, Swies J: On the mechanism of antithrombotic action of flavonoids. Biochem Pharmacol 1987;36:317-21.

66. Guo S-C, Chen S-C, Chen L-H, Wu J-B, Wang J$\mathrm{P}$, Teng C-M: Potent antiplatelet, anti-inflammatory and antiallergic isoflavanquinones fron the roots of Abrus precatorius. Planta Med 1995;61:307-12

67. Menkin V: Anti-inflammatory activity of some water-soluble bioflavonoids. Am J Physiol 1959;196:1205-10.

68. Busse WW, Kopp DE, Middleton E: Flavonoid modulation of human neutrophil function. J Allergy Clin Immunol 1984;73:801-9.

69. Tanno Y, Kakuta Y, Aikawa T, Shindoh Y, Ohno I, Takishima T. Effects of Qing-Fei-Tang (Seihai-to) and baicalein, its main component flavonoid, on lucigenin-dependent chemiluminescence and leukotriene $B_{4}$ synthesis of human alveolar macrophages. Am J Chin Med 1988; 16:145-54.

70. van der Nat JM, van der Sluis WG, t'Hart LA, Van Dijk H, de Silva KTD, Labadie RP: Activityguided isolation and identification of Azadirachta indica bark extract constituents which specifically inhibit chemiluminescence production by activated human polymorphonuclear leukocytes. Planta Med 1991:57:65-8.

71. Limasset B, Le Doucen C, Dore J-C, Ojasoo T, Damon M, de Paulet AC: Effects of flavonoids on the release of reactive oxygen species by stimulating human neutrophils: multivariate analysis of structure-activity relationships. Biochem Pharmacol 1993;46:1257-71.

72. Wagner H: Search for new plant constituents with potential antiphlogistic and antiallergic activity. Planta Med 1989;55:235-41

73. Comèl M, Laszt L, eds.: Clinical pharmacology: Flavonoids and the vascular wall. Basel: Karger, 1972

74. Voelter W, Jung G, eds.: O-( $\beta$-Hydroxyethyl)rutoside - experimentelle und klinische Ergebnisse.Berlin: Springer, 1978.

75. Hahn G, Mayer A: Die Mariendistel. Österr Apoth-Ztg 1981;35:849-53.

76. Koch H: Leberschutz-Therapeutica (2. Teil). Pharm unserer Z 1980;9:65-74.

77. Conn HO, ed.: International workshop on (+)cyanidanol-3 in diseases of the liver. London: Royal Society of Medicine/Academic Press, 1981.

78. Iwamoto M, Ishizaki T, Sato T: Klinische Wirkung von Crataegutt ${ }^{R}$ bei Herzerkrankungen ischämischer und/oder hypertensiver Genese. Planta Med 1981;42:1-16.

79. De Smet PAGM: An introduction to herbal pharmacoepidemiology. J Ethnopharmacol 1993; 38:197-208.

80. Hopfenmüller W: Nachweis der therapeutischen Wirksamkeit eines Ginkgo biloba-Spezialextraktes. Meta-Analyse von 11 klinischen Studien bei Patienten mit Hirnleistungsstörungen. Arzneim-Forsch 1994;44: 1005-13.

81. Bibby MC, Double JA: Flavone acetic acid - from laboratory to clinic and back. Anti-Cancer Drugs 1993;4:3-17.

82. Hertog MGL, Kromhout D, Aravanis C Blackburn H, Buzina R, Fidanza $F$ et al: Flavonoid intake in long-term risk of coronary heart disease and cancer in the Seven Countries
Study. Arch Intern Med 1995;155:381-6.

83. Bentsàth $\mathrm{A}$, Rusznyàk $\mathrm{S}$, Szent-Györgyi A: Vitamin nature of flavones. Nature 1936; 138:798.

84. Bentsàth A, Rusznyàk S, Szent-Györgyi A: Vitamin P. Nature 1937;139:326-7.

85. Harborne JB: Current trends in the chromatographic analysis of plant phenolics. In: Vlietinck AJ \& Dommisse RA, eds. Advances in medicinal plant research. Stuttgart: Wissenschaftliche Verlagsgesellschaft, 1985: 135-51.

86. Iio M, Uyeda M, Iwanami T, Nakagawa Y: Flavonoids as a possible preventive of dental caries. Agric Biol Chem 1984;48:2143-5.

87. Osawa $K$, Yasuda $H$, Maruyama $T$, Morita $H$, Takeya K, Itokawa H: Isoflavanones from the heartwood of Swartzia polyphylla and their antibacterial activity against cariogenic bacteria. Chem Pharm Bull 1992;40:2970-4

88. Nakagawa M, Nakanishi K, Darko LL, Vick JA: Structures of cabenegrins A-I and A-II, potent anti-snake venoms. Tetrahedron Lett 1982;23: 3855-8.

89. Shiseido Co. Ltd: Hair cosmetic. Japanese patent 62-153211, 1987

90. Cody V, Middleton E, Harborne JB, eds.: Plant flavonoids in biology and medicine. Biochemical, pharmacological and structure-activity relationships. New York: Alan R. Liss, 1986.

91. Cody V, Middleton E, Harborne JB, BeretzA, eds.: Plant flavonoids in biology and medicine II. Biochemical, cellular and medicinal properties. New York: Alan R. Liss, 1988.

92. Das NP, ed.: Flavonoids in biology and medicine III: Current issues in flavonoids research. Singapore: National University of Singapore, 1990.

93. Pathak D, Pathak K, Singla AK: Flavonoids as medicinal agents - Recent advances. Fitoterapia 1991;62:371-89.

94. Wilson RH, Mortarotti TG, Doxtader EK Toxicity studies on rutin. Proc Soc Exptl Biol Med 1947;64:324-7

95. Ambrose AM, Robbins DJ, DeEds, F: Comparative toxicities of quercetin and quercitrin. $\mathrm{J}$ Am Pharm Ass Sci Ed 1952; 41:119-22.

96. Lina BAR, Dreef-van der Meulen HC, Leegwater DC: Subchronic (13-week) oral toxicity of neohesperidin dihydrochalcone in rats. Food Chem Toxicol 1990;28:507-13.

97. Willhite $\mathrm{CC}$ : Teratogenic potenital of quercetin in the rat. Food Chem Toxicol 1982;20:75-9.

98. Daniel PT, Holzschuh J, Berg PA: The pathogenesis of cianidanol-induced fever. Eur J Clin Pharmacol 1988;34:241-7.

99. Jaeger A, Wälti M, Neftel K: Side effects of flavonoids in medical practice. In: Cody V, Middleton $\mathrm{E}$, Harborne JB, Beretz A, eds. Plant flavonoids in biology and medicine II. Biochemical, cellular and medicinal properties. New York: Alan R. Liss, 1988:379-94.

100.Edwards JM, Raffauf RF, LeQuesne PW: Antineoplastic activity and cytotoxicity of flavones, isoflavones and flavanones. J Nat Prod 1979;42:85-91.

101.Boersma HH, Woerdenbag HJ, Bauer J, Scheithauer W, Kampinga $\mathrm{HH}$, Konings AWT: Interaction between the cytostatic effects of quercetin and 5-fluorouracil in two human colorectal cancer cell lines. Phytomedicine 1994; 1: 239-44.

102. Wall ME: Antimutagenic agents from natural products. J Nat Prod 1992;55:1561-8.

103.Shamon LA, Pezzuto JM: Plant antimutagens: A review and strategy for the identification of therapeutically useful agents. In: Wagner $\mathrm{H}$, Farnsworth NR, eds. Economic and medicinal plant research, volume 6. London: Academic Press, 1994:235-97.

104.Pamukcu AM, Yalciner S, Hatcher JH, Bryan GT: Quercetin, a rat intestinal and bladder carcinogen in bracken fern (Pteridium aquilinum). Cancer Res 1980;40:3468-72.

105.Hertog MGL, Feskens EJM, Holman PCH, Katan $\mathrm{MB}$, Kromhout D: Dietary flavonoids and cancer risk in the Zutphen elderly study. Nutr Cancer 1994:22:175-84.

106. Hertog MGL, Hollman PCH, van de Putte B: Content of potentially anticarcinogenic flavonoids in tea infusions, wines and fruit juices. J Agr Food Chem 1993;41:1242-6.
107.Anthony MS, Clarkson TB, Hughes CL, Morgan TM, Burke GL: Soybean isoflavones improve cardiovascular risk factors without affecting the reproductive system of peripubertal rhesus monkey. J Nutr 1996; 126: 43-50.

108. Bahorun T, Trotin F, Pommery J, Vasseur J, Pinkas M: Antioxidant activities of Crataegus monogyna extracts. Planta Med 1994:60:323-8.

109.Schüssler M, Hölzl J, Frick U: Myocardial effects of flavonoids from Crataegus species. ArzneimForsch 1995;45:842-5.

110. Al Makdessi S, Sweidan H, Müllner S, Jacob R: Myocardial protection by pretreatment with Crataegus oxyacantha. An assessment by means of the release of lactate dehydrogenase by the ischemic and reperfused Langendorff heart. Arzneim-Forsch 1996;46:25-7.

111. Knekt P, Järvinen R, Reunanen A, Maatela J: Flavonoid intake and coronary mortality in Finland: a cohort study. Brit Med J 1996; $312: 478$ 81

112. Keli SO, Hertog MGL, Feskens EJM, Kromhout D: Dietary flavonoids, antioxidant vitamins, and incidence of stroke. Arch Intern Med 1996;156: 637-42.

113. Merfort I, Heilmann J, Weiss M, Pietta P, Gardana $\mathrm{C}$ : Radical scavenger activity of three flavonoid metabolites studied by inhibition of chemiluminescence in human PMNs. Planta Med 1996 62: 289-92

114. Kawabe M, Tomano S, Shibata M-A, Hirose M, Fukushima S, Ito N: Subchronic toxicity study of methyl hesperidin in mice. Toxicol Lett 1993; 69: 37-44.

115. Schmalle HW, Jarchow OH, Hausen BM, Schulz $\mathrm{K}-\mathrm{H}$ : Aspects of the relationships between chemical structure and sensitizing potency of flavonoids and related compounds. In: Cody V Middleton E, Harborne JB, eds. Plant flavonoids in biology and medicine. Biochemical, pharmacological and structure-activity relationships. New York: Alan R Liss, 1986:387-90.

116. Hausen BM, Bruhn G, Koenig WA: New hydroxyisoflavans as contact sensitizers in cocus wood Brya ebenus DC (Fabaceae). Contact Dermatitits 1991:25:149-55.

117. Hausen BM, Wollenweber E, Senff H, Post B Propolis allergy (I). Origin, properties, usage and literature review. Contact Dermatitis 1987;17: 163-70

118. Hausen BM, Wollenweber E, Senff H, Post B. Propolis allergy (II): The sensitizing properties of 1,1-dimethylallylic caffeic acid ester. Contact Dermatitis 1987;17:171-7.

119. Hausen BM, Evers P, Stüwe H-T, König WA, Wollenweber E: Propolis allergy (IV). Studies with further sensitizers from propolis and constituents common to propolis, poplar buds and balsam of Peru. Contact Dermatitis 1992;26:36 44

120.Whitten PL, Lewis C, Russell E, Naftolin F: Potential adverse effects of phytoestrogens. J Nut 1995; 125:771S-6S.

121. Barnes S: Effect of genistein on in vitro and in vivo models of cancer. J Nutr 1995;125:777S-83S.

122. Herman C, Adlercreutz H, Goldin BR, Gorbach SL, Höckerstedt KAV, Watanabe S et al.: Soybean phytoestrogen intake and cancer risk. J Nutr 1995 ; 125:757S-70S.

123. Dunnick J, Hailey JR: Toxicity and carcinogenicity studies of quercetin, a natural componen of foods. Fundam Appl Toxicol 1992; 19: 423-31.

124. Ito N: Is quercetin carcinogenic? Jpn J Cancer Res 1992;83:312-4

125.Stavric B: Quercetin in our diet: From potent mutagen to probable anticarcinogen. Clin Biochem 1994; 27: 245-8.

126. Das A, Wang JH, Lien EJ: Carcinogenicity, mutagenicity and cancer preventing activities of flavonoids: A structure-system-activity relationship (SSAR) analysis. Progr Drug Res 1994;42:13366.

127. Hollman PCH, v d Gaag M, Mengelers MJB, van Trijp JMP, de Vries JHM, Katan MB: Absorption and disposition kinetics of the dietary antioxidant quercetin in man. Free Rad Biol Med 1996;21: 703-7.

128. Paganga G, Rice-Evans CA: The identification of flavonoids as glycosides in human plasma. FEBS Lett 1997;401:78-82. 